\title{
PROJETO ARQUEOLÓGICO FUNDO DO BAÚ
}

Wagner Magalhães ${ }^{1}$

\section{RESUMO}

O presente projeto é um ensaio realizado na ocasião de minha participação na disciplina Fundamentos da Prática Arqueológica ${ }^{2}$, ministrada no âmbito do curso de especialização Lato Sensu em Arqueologia, História e Sociedade da Universidade de Santo Amaro - UNISA. Concebido de maneira lúdica, teve o intuito de analisar os processos de deposição da cultura material relacionada a uma das quadras do sítio arqueológico LQ, localizado em um terraço habitacional na zona oeste do município de São Paulo, no estado de São Paulo, Brasil, com objetivo de buscar correlações sobre os padrões de deposição, além dos aspectos simbólicos e temporais no processo de deposição desta área. Tratase de um ensaio no qual se realiza uma análise técnica e tipológica com a intenção de reconstruir as sequências operacionais dessa área arqueológica.

Palavras-chave: Cultura Material; Processo de Deposição; Sequência Operacional; Estratigrafia; LQ.

\section{ABSTRACT}

This project is a test performed on the occasion of my participation in the discipline Fundamentals of Archaeological Practice, delivered in the course of specialization Sensu Lato in Archaeology, History and Society at the University of Santo Amaro - UNISA. Designed in a playful manner, aimed to analyze the material culture deposition processes related to one of the blocks from the archaeological site LQ, located in a residential terrace in the west of São Paulo, in São Paulo, Brazil, with the objective of seeking correlations on the deposition patterns, beyond the symbolic and temporal aspects in this area deposition process. This is an essay in which performs a technical and typological analysis with the intention of rebuilding the operational sequences of this archaeological area.

Keywords: Material Culture; Deposition process; Operating sequence; Stratigraphy; LQ.

\section{RESUMEN}

Este proyecto es una prueba realizada con motivo de mi participación en la disciplina Fundamentos de la Práctica Arqueológica, entregados en el curso de especialización en Lato Sensu de Arqueología, Historia y Sociedad en la Universidad de Santo Amaro - UNISA. Pensado en una manera lúdica, con

\footnotetext{
${ }^{1}$ Pós-graduando do MAE-USP.

${ }^{2}$ Disciplina ministrada no outono de 2012 pela Prof. Dr. Carolina Kesser Barcellos Dias.
}

\begin{tabular}{|l|l|l|l|l|l|l|}
\hline (C) Rev. Arqueologia Pública & Campinas, SP & v. 10 & n. 1 & p. 86-108 & MAR. 2016 & ISSN 2237-8294 \\
\hline
\end{tabular}




\section{Revista de Arqueologia Pública}

el objetivo de analizar los procesos de deposición de cultivo de material relacionado con uno de los bloques de la zona arqueológica $L Q$, situado en una terraza residencial en el oeste de Sao Paulo, en Sao Paulo, Brasil, com el objetivo de buscar correlaciones en los patrones de deposición, más allá de los aspectos simbólicos y temporales en este proceso de deposición. Se trata de un ensayo en el que se realiza un análisis técnico tipológico y con la intención de reconstruir las secuencias operativas de esta zona arqueológica.

Palabras clave: Cultura material; Proceso de deposición; Secuencia de manejo; estratigrafía; LQ.

\section{INTRODUÇÃO}

"Mostre-me tuas bagagens e te direi quem és". O slogan desse anúncio, veiculado em 1921, na França, pela marca Louis Vuitton, trazia o espírito dos viajantes da época: malas enormes que transportavam por meses objetos em trens e transatlânticos.

Se hoje as pessoas trocam de mala a cada nova viagem, no final de 1854, ano em que Louis Vuitton fez seu primeiro baú, viajantes e bagagens tinham uma relação muito íntima. As malas recebiam selos dos países pelos quais passavam e ajudavam a contar as histórias das viagens.

Dos transatlânticos aos trens, dos automóveis às primeiras aeronaves, os baús viajaram no tempo e através das fronteiras, adaptando-se aos meios de transporte e às mudanças no ritmo de vida, ganhando cada vez mais donos e significados.

É nesse espírito que esse ensaio intitulado Projeto Arqueológico Fundo do Baú foi concebido. O baú é um utensílio que até hoje se encontra presente na vida de famílias tradicionais de origem europeia, seja como um simples artefato de decoração, ou como um eficiente utensílio para armazenar as mais diferentes coisas que, de alguma maneira, se constituem em bens de extrema importância para o seu detentor.

Realizando uma analogia entre o universo teórico e metodológico inerente à prática da arqueologia e nossa vida cotidiana, o presente ensaio coloca em prática alguns dos conceitos costumeiramente adotados pela ciência durante pesquisas arqueológicas. Transpondo esses conceitos para dentro de casa, de forma minimalista, podemos experimentar a aplicação de conceitos e paradigmas que muitas vezes só nos são lançados quando defronte a situações reais de campo e, convenhamos, num momento em que definitivamente não se pode errar.

Nada melhor do que praticar e, deste modo, procurei dentro da minha casa um objeto que, apesar de fazer parte do meu cotidiano, não tivesse uma relação intimista com o meu dia-a-dia. Tinha que ser alguma coisa que me despertasse a curiosidade e que definitivamente eu nunca tivesse mexido. Isso ajudaria a manter-me de certa forma imparcial na compreensão dos motivos e razões que fizeram com que aquilo que viria a se constituir meu objeto de pesquisa estivesse disposto daquele modo. Pois bem, tomei como balão de ensaio um rústico baú de madeira, que minha esposa, quando do nosso casamento, fez questão de integrar ao nosso mobiliário. A única informação que eu tinha era

\begin{tabular}{|l|l|l|l|l|l|l|}
\hline (C) Rev. Arqueologia Pública & Campinas, SP & v. 10 & n. 1 & p. 86-108 & MAR. 2016 & ISSN 2237-8294 \\
\hline
\end{tabular}




\section{Revista de Arqueologia Pública}

a de que aquele baú encontrava-se na sua família há pelo menos três gerações e testemunhou a acumulação de bens pessoais relacionados principalmente à formação de enxovais, não só dela mas também de suas ancestrais diretas, mãe e avó materna.

Desde que nos mudamos para nossa casa, aquele baú encontrava-se ali, num canto da sala, servindo de aparador, inerte, imóvel. Vivendo conosco de forma tímida e discreta a tal ponto que eu nunca havia me perguntado o que lá dentro repousaria. E foi assim que o velho baú de carvalho veio a se constituir uma de minhas primeiras quadrículas.

Assim, o presente projeto foi concebido com o intuito de analisar os processos de deposição da cultura material relacionada a uma das quadrículas localizada na Quadra B do sitio arqueológico por nós nomeado $L Q$, em referência às iniciais da Sra. Luciana Quadros, matriarca e proprietária do local. A Quadrícula B1, que no presente projeto se constitui em nossa área de estudo, é formada por um baú rústico de madeira talhada, locado na Quadra B do sítio que se encontra localizado no 13ํㅜ terraço habitacional, voltado a $156^{\circ}$ SE sob as coordenadas $23^{\circ} 34^{\prime} 46^{\prime \prime} \mathrm{S}, 46^{\circ} 36^{\prime} 36^{\prime \prime} \mathrm{O}^{3}$, e identificado como unidade 132-B do conjunto de duas áreas arqueológicas.

Por meio de uma análise técnica e tipológica, o Projeto Arqueológico Fundo do Baú buscou identificar correlações sobre o padrão de deposição contemporânea nessa quadrícula, além de seus aspectos simbólicos e temporais no processo de deposição, com a intenção de possivelmente contribuir na reconstrução das sequências operacionais dessa área arqueológica.

\section{ÁREA DE PROSPECÇÃO}

Antes de realizarmos uma descrição da área de estudo, cabe ressaltar a importância das atividades que precedem esta etapa, como a descrição da equipe, quando são relacionados os profissionais envolvidos no estudo, o cronograma de execução, a descrição da região geográfica, e o levantamento documental (cartas, mapas, relatos, fotografias, publicações etc.) tudo que possa corroborar o estudo a ser desenvolvido.

Nosso trabalho de prospecção restringiu-se ao $13^{\circ}$ terraço habitacional do conjunto "B", mais especificamente na unidade 132, aqui denominada Sitio LQ, voltada a 156 SE. O sitio LQ apresenta um área equivalente a $120 \mathrm{~m}^{2}$ e possui as seguintes características locacionais:

\footnotetext{
${ }^{3}$ Tanto as coordenadas como os endereços aqui apresentados são fictícios.
}

\begin{tabular}{|l|l|l|l|l|l|l|}
\hline (C) Rev. Arqueologia Pública & Campinas, SP & v. 10 & n. 1 & p. 86-108 & MAR. 2016 & ISSN 2237-8294 \\
\hline
\end{tabular}




\section{Revista de Arqueologia Pública}

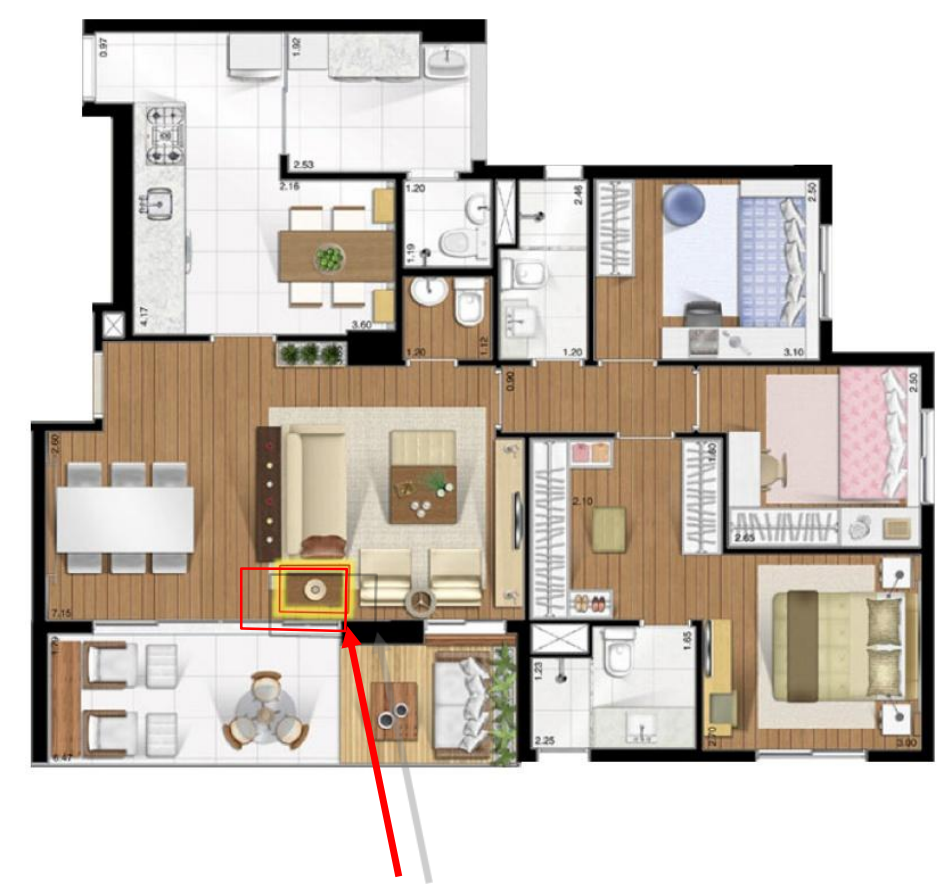

Figura 1 - Planta baixa do Sitio Arqueológico LQ com detalhamento da Quadricula B1 estudada, inserida na Quadra B.

A Quadricula B1, que no presente projeto se constituiu em nossa área de estudo, era formada por um baú rústico de madeira talhada nas dimensões $78 \times 53 \times 47 \mathrm{~cm}$ (largura, altura, profundidade), e locado na Quadra B do "sítio arqueológico".

Segundo relato oral da proprietária, o rústico baú de madeira encontra-se na família há pelo menos três gerações, e testemunhou a acumulação de bens pessoais, relacionados principalmente à formação de enxovais. O baú que tem como matéria prima o carvalho de lei e ferragens de ferro fundido, e é originário de Portugal, chegando no Brasil acompanhando sua avó materna, em meados da década de 1920 e, desde então, tem permanecido na família, antes propriedade de sua mãe e, mais recentemente, herdado pela proprietária quando da preparação de seu enxoval de casamento.

Atualmente, o baú encontra-se exercendo uma função diferente da que habitualmente costumamos ver. O baú encontra-se locado na Quadra B que é constituída basicamente pela sala de estar da residência, local destinado à reunião familiar e à prática de atividades de entretenimento $e$ socialização. O baú encontra-se locado de forma harmônica com os demais móveis, mas exercendo o papel de um objeto de decoração e, tal como uma mesa lateral, oferecendo suporte a objetos de decoração (vaso e livros) e artefatos de uso cotidiano, como telefone e controles remotos dos equipamentos eletroeletrônicos existentes no ambiente.

O objetivo de se escavar o referido baú foi o de compreender o padrão de deposição e identificar a eventual ocorrência de correlações culturais entre o material depositado e os artefatos existentes na superfície das áreas de intervenção direta (AID) e área de intervenção indireta (AII), nas

\begin{tabular}{|l|l|l|l|l|l|l|}
\hline (C) Rev. Arqueologia Pública & Campinas, SP & v. 10 & n. 1 & p. 86-108 & MAR. 2016 & ISSN 2237-8294 \\
\hline
\end{tabular}




\section{Revista de Arqueologia Pública}

quadras do entorno.

A justificativa reside no fato de que ainda que no contexto previamente estabelecido o referido baú tenha adquirido uma segunda funcionalidade, enquanto seu uso na forma de mesa, acredita-se que sua funcionalidade primeira, aquela relacionada ao hábito de guardar bens com um determinado valor agregado, seja do ponto de vista econômico, simbólico ou sentimental, deva prevalecer até os dias atuais.

\section{ABORDAGEM METODOLOGICA}

Os procedimentos de pesquisa empregados no presente ensaio seguiram as orientações e diretrizes do Instituto de Patrimônio Histórico e Artístico Nacional, definidos pela Portaria ํㅡ. 230/2002, que delibera sobre os procedimentos necessários à compatibilização de licenças ambientais com estudos preventivos de arqueologia (BASTOS \& TEIXEIRA, 2005).

Assim, o enfoque metodológico adotado para o estudo das interações entre meio ambiente e potencial arqueológico apresenta vínculos com pressupostos da Arqueologia Contextual (Contextual Archaeology) que, conforme Waters (1992), está relacionada a uma abordagem sistêmica na qual a recuperação de componentes contextuais do ecossistema humano é usada para a interpretação de aspectos de estabilidade e mudança cultural.

Assim sendo, o estudo dos elementos naturais em análise arqueológica constitui importante ferramenta preditiva para o diagnóstico de áreas quanto ao potencial de ocorrência de sítios e na pesquisa sobre a influência dos aspectos ambientais nos padrões de ocupação e das atividades de grupos humanos pretéritos.

Destarte, na definição dos métodos para a elaboração da investigação arqueológica foram levadas em conta não somente as especificidades técnicas da quadricula B1, mas também as características ambientais da área onde a mesma está inserida. E para a avaliação do potencial de ocorrência de vestígios de interesse arqueológico nas áreas de influência do sítio foram sopesados os seguintes tópicos:

Contextualização arqueológica: consiste no levantamento secundário de dados arqueológicos, tais como: levantamento do histórico de pesquisas anteriores; verificação da existência de sítios registrados; obtenção e análise de sínteses regionais; reconhecimento de coleções existentes em instituições museológicas; busca por informações orais; reconhecimento das características dos indícios e das estruturas correlatas; apontamento dos locais de ocorrência já registrados e avaliação do potencial arqueológico da área como um todo;

Contextualização etno-histórica: tentativa de impetração de uma visão regional e local dos aspectos e informações históricas e étnicas existentes, a fim de estabelecer uma relação preditiva que

\begin{tabular}{|l|l|l|l|l|l|l|}
\hline (C) Rev. Arqueologia Pública & Campinas, SP & v. 10 & n. 1 & p. 86-108 & MAR. 2016 & ISSN 2237-8294 \\
\hline
\end{tabular}




\section{Revista de Arqueologia Pública}

possa avaliar o potencial da área, com a presença de indícios relacionadas a aspectos simbólicos e/ou culturais nas atividades humanas pretéritas, envolvidas no processo de deposição dessa área.

Na prática, os procedimentos para a elaboração do presente projeto arqueológico no sitio $L Q$ foram desenvolvidos a partir dos três eixos básicos de investigação:

Levantamento sistemático da bibliografia especializada disponível: através de consulta à bibliografia relacionada à história e à arqueologia regional, e pesquisa junto ao Cadastro Nacional de Sítios Arqueológicos do IPHAN;

Realização de investigações de campo: através do reconhecimento da área com utilização de material cartográfico e obtenção de pontos notáveis, com auxílio de aparelho GPS, a fim de referenciar a área estudada; vistoria arqueológica na área de influência direta, com caminhamento extensivo e observações oportunísticas em cada uma das quadras do sítio, sendo possível a visualização da superfície do terreno; busca de informações orais junto a moradores e frequentadores da região, com objetivo de se obter informações sobre a existência de vestígios de interesse arqueológico nas áreas de influência.

Síntese, análise e diagnóstico das informações obtidas, a partir dos itens anteriormente expostos.

O método de escavação foi o de superfícies amplas por níveis artificiais (LEROI-GOURHAN, 1972), sendo executados quatro níveis de decapagens com profundidade de $10 \mathrm{~cm}$ cada, em uma área total de $0,36 \mathrm{~m}^{2}(0,78 \times 0,47)$, sendo evidenciados um total de 22 remanescentes culturais que serão devidamente descritos e analisados.

Para análise dos remanescentes culturais foram adotados os procedimentos sugeridos por Morais (1983) e Fagundes $(2004,2005)$. Nessa abordagem, o material é passado por uma série de triagens, de forma que todos os itens possam ser analisados em seus atributos individuais e também comparados entre si, compreendendo as relações que ocorreram entre eles, ao mesmo tempo em que os resultados entre os diversos conjuntos de remanescentes culturais possam ser relacionados.

Deste modo são analisados: tipologia (artefato, forma, função); tipo de matéria-prima; estado da superfície (integridade); dimensões da peça e suas relações (comprimento, largura, espessura e peso); sua classificação morfológica; traços de utilização; acidentes. Todos estes passos são seguidos tendo em vista a possibilidade da reconstrução de parte da cadeia operatória (FAGUNDES, 2004).

Conforme Bleed (2001), o uso do conceito etnográfico de cadeias operatórias se tornou extremamente popular entre a comunidade científica (sobretudo a francesa), isto por oferecer uma metodologia mais concreta que permitiu ultrapassar análises unicamente tipológicas e, sobretudo, porque permitiu compreender o mundo material enquanto sistema, avançando nas discussões sobre os aspectos cognitivos das técnicas (BLEED, 2001:107-108).

Para Lemonnier (1986, 1992), o estudo de cadeias operatórias é, antes de tudo, a base 


\section{Revista de Arqueologia Pública}

material da antropologia das técnicas, um meio pelo qual podemos compreender não apenas a cultura material, mas as técnicas como sistema, nesse caso, buscando o entendimento dos processos mentais e materiais envolvidos na tecnologia propriamente dita.

Portanto, neste ensaio, partimos do princípio que o uso do conceito de cadeia operatória nos possibilita compreender todo o comportamento envolvido na concepção do artefato assim como no seu processo de deposição a partir dos gestos envolvidos, dos padrões mentais, da base cognitiva, dos produtos e sub-produtos relacionados, enfim, dos processos levados a cabo pelo ator depositante de acordo com os padrões culturais da sociedade em que este se insere.

Sob esse viés, o estudo de cadeia operatória revela a dinâmica de um sistema técnico específico, bem como o papel que esse sistema ocupa dentro dos demais sistemas técnicos e dentro da própria tecnologia, sendo essa sua peculiaridade principal: a análise dos conceitos e conhecimentos envolvidos desde a manufatura ao descarte de uma dada cultura material (CRESWELL, 1996, p. 43).

Logo, o uso deste conceito tem refinado as observações dos artefatos e assentamentos, demonstrando que os estudos puramente tipológicos não respondem às questões básicas para compreender a dinâmica cultural no passado, da relação entre os sistemas técnicos, do sistema tecnológico e de seu papel diante dos demais sistemas componentes de uma sociedade.

\section{RESULTADOS}

$\mathrm{Na}$ ocasião das atividades de campo, realizou-se preliminarmente um diagnóstico não interventivo de cada uma das quadras do sitio LQ (Fig. 2), com o objetivo de verificar eventuais evidências de características culturais e hábitos no processo de assentamento da sociedade que ali residiu.

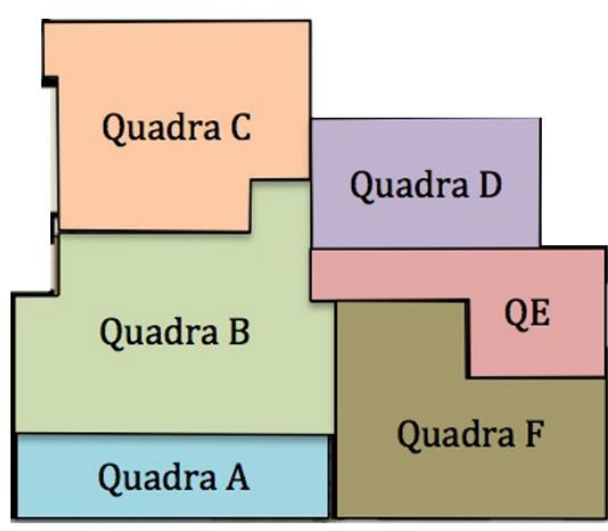

Quadra A = Varanda destinada a atividades de lazer e meditação.

Quadra B = Sala destinada a atividades de entretenimento e socialização.

Quadra C = Cozinha e Área de Serviços destinada à elaboração de alimentos e serviços domésticos.

Quadra D = Toalete e escritório destinado a atividades intelectuais.

Quadro E = Circulação e dormitório.

Quadro F $=$ Toalete e dormitório. 


\section{Revista de Arqueologia Pública}

Figura 2 - Delimitação das Quadras sobre a planta baixa do Sitio Arqueológico LQ.

Dentre os resultados mais significantes podemos relatar:

QUADRA A: Varanda destinada a atividades de lazer e meditação; forte influência oriental no processo de decoração; evidências materiais de práticas rituais relacionadas ao Budismo; presença de altar, incensário, e fonte com imagem de Buda, além de inúmeros livros de estudo da prática filosófica budista.

QUADRA B: Sala destinada a atividades de entretenimento e socialização. É nela que se encontra locado o baú delimitado como quadricula B1. As evidências materiais de características culturais identificadas nessa Quadra restringem-se a três livros depositados no Nível "Zero" da quadricula B1, que, apesar de serem aqui relatados, serão considerados como inseridos em nível antrópico a ser desconsiderado. Dois dos livros estão relacionados a fotografia e um está relacionado a filosofia, o que denota além do interesse pela leitura, o apreço pelas artes.

QUADRA C: Cozinha e Área de Serviços destinada à elaboração de alimentos e serviços domésticos. Não se evidenciou afloramento de características culturais e hábitos nessa Quadra.

QUADRA D: Toalete e escritório destinado a atividades intelectuais. Assim como nas Quadras $A$ e $B$ verifica-se a evidência material de características culturais relacionadas ao hábito da leitura e da prática Budista na área que compreende um escritório; presença de incensário, imagem de Buda, além de inúmeros livros dos mais variados temas.

QUADRA E: Circulação e Dormitório. Não se evidenciou afloramento de características culturais e hábitos nessa Quadra.

QUADRA F: Toalete e Dormitório. Não se evidenciou afloramento de características culturais e hábitos nessa Quadra.

Com base nas evidências culturais levantadas nas Quadras A, B e D localizadas no entorno da Quadricula B1, procurou-se durante o processo de decapagem buscar eventuais correlações entre a cultura material depositada e essas práticas cotidianas. A Quadricula B1 é formada por um baú rústico de carvalho, de origem portuguesa nas dimensões $78 \times 53 \times 47 \mathrm{~cm}$ (largura, altura, profundidade) locado na extremidade Sul da Quadra B, junto à linha limítrofe entre essa quadra e a Quadra A do sitio arqueológico LQ (Fig. 1).

A partir de uma escavação se estabelecem dois tipos de registro. Um, o registro das coisas tangíveis, que podem ser vistas e examinadas uma vez que a escavação está acabada. O outro, o registro das coisas que foram destruídas pelo ato de escavar e que devem ser registradas, tendo em vista que nunca mais serão vistas. Os dados deste tipo de registro são estruturais e contextuais (MCINTOSH, 1986). 


\section{Revista de Arqueologia Pública}

Realizaram-se quatro decapagens, cada uma com $10 \mathrm{~cm}$ de profundidade, totalizando $40 \mathrm{~cm}$ de profundidade a partir do N0 (nível zero). A relação dos artefatos encontrados pode ser verificada na Tabela 1. Após coletado, cada artefato foi retirado de seu invólucro de proteção, limpo, separado para posteriormente ser analisado tanto do ponto de vista morfológico como tipológico, sendo posteriormente registrado de forma detalhada por meio de anotações, fotos e mapeamento (JOUKOWSKY, 1986).

Dentre os métodos de registro adotados, foi utilizada como forma de organização das unidades estratigráficas a matriz elaborada por Edward C. Harris (1991), que consiste de um diagrama com todas as unidades estratigráficas exploradas, reconstituindo o processo cronológico do antes e depois, assim como da contemporaneidade. As unidades estratigráficas constituem, cada uma delas, realidades que podem ser individualizadas pelas suas próprias características que lhe são intrínsecas e, principalmente, pela sua posição em relação às outras unidades estratigráficas. Segundo Harris,

Las "unidades de estratificación" arqueológica representan un aspecto arqueológico del ciclo del tiempo, son de caráter universal y se hallan en todos los yacimientos arqueológicos del mundo. La estratificación arqueológica en sí misma representa el ciclo del tiempo, porque está formada por los mismos procesos repetitivos, es decir, deposición o degradación. Esta es la razón por la que el arqueólogo debería ser capaz de trabajar de manera eficiente en cualquier yacimiento, si ha sido verdadeiramente formado en la teoría y en la práctica de la estratigrafía arqueológica (HARRIS, 1991:68).

Foram, ainda, elaboradas pranchas com os desenhos das quadrículas e de cada um dos níveis estratigráficos explorados (Figs. 3 a 6). Foram preenchidas planilhas de controle com as orientações sobre os achados, cálculos e gráficos que pudessem auxiliar a equipe arqueológica durante e após o processo de evidenciação do material. 


\section{Revista de Arqueologia Pública}

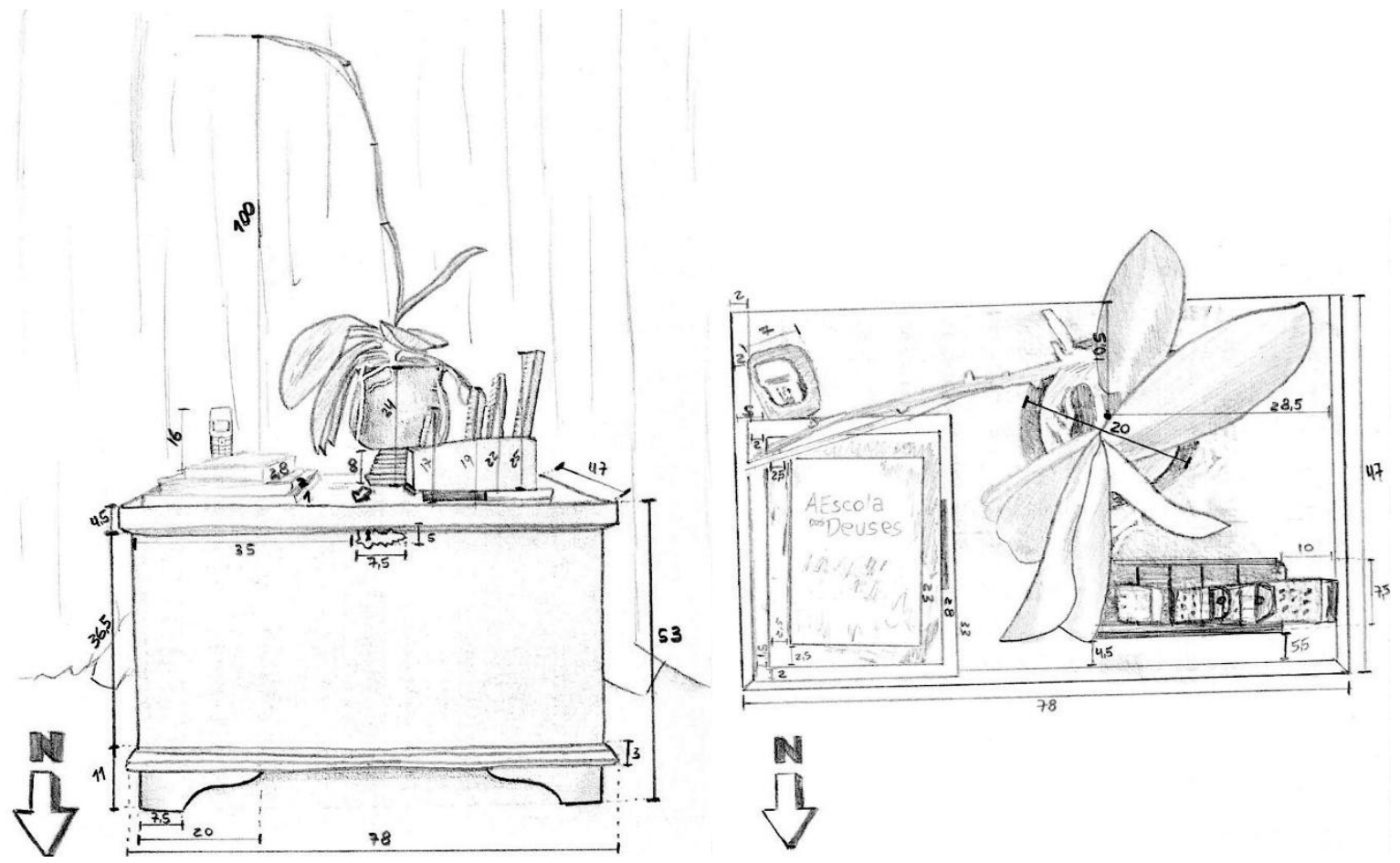

Figura 3 - Visão frontal da quadricula a ser explorada

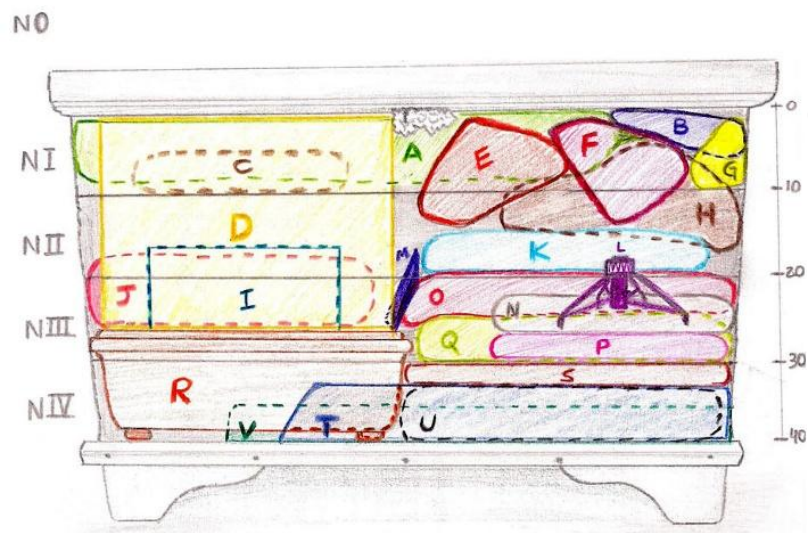

Figura 5 - Estratigrafia da quadricula
Figura 4 - Visão superior da quadricula a ser explorada

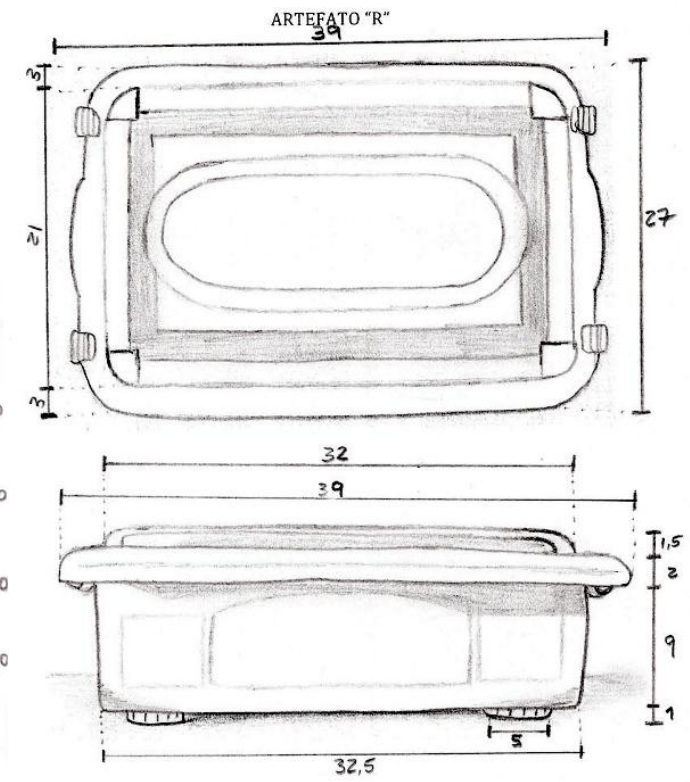

Figura 6 - Visão do artefato "R" e respectivas dimensões 
Os dados obtidos em laboratório foram tabulados e dispostos em tabelas e gráficos para uma melhor compreensão.

\begin{tabular}{|c|c|c|c|c|c|c|c|c|c|c|c|}
\hline $\begin{array}{l}\text { Quad } \\
\text { ricula }\end{array}$ & $\begin{array}{l}\text { Ite } \\
\text { m }\end{array}$ & $\begin{array}{c}\text { Tom } \\
\text { bo }\end{array}$ & $\begin{array}{c}\text { Tipo } \\
\text { de } \\
\text { Materi } \\
\text { al }\end{array}$ & $\begin{array}{c}\text { Comp } \\
\text { osiçã } \\
0\end{array}$ & $\begin{array}{l}\text { Supe } \\
\text { rfície }\end{array}$ & $\begin{array}{c}\text { Nível } \\
\text { Estrati } \\
\text { gráfico }\end{array}$ & $\begin{array}{l}\text { Quant } \\
\text { idade }\end{array}$ & $\begin{array}{c}\text { Mate } \\
\text { rial } \\
\text { Cole } \\
\text { tado }\end{array}$ & $\begin{array}{c}\text { Descri } \\
\text { ção } \\
\text { de } \\
\text { Uso }\end{array}$ & $\begin{array}{c}\text { Obser } \\
\text { vaçõe } \\
\text { s }\end{array}$ & $\begin{array}{c}\text { Dat } \\
\text { açã } \\
0\end{array}$ \\
\hline B1 & 1 & $\begin{array}{l}\text { Aus } \\
\text { ente }\end{array}$ & $\begin{array}{c}\text { Vaso } \\
\text { de } \\
\text { vidro } \\
\text { preto }\end{array}$ & Cristal & $\begin{array}{l}\text { Lisa / } \\
\text { Preta }\end{array}$ & No & 1 & não & $\begin{array}{c}\text { Decor } \\
\text { ação }\end{array}$ & $\begin{array}{c}\text { Camad } \\
\text { a } \\
\text { Estére } \\
0\end{array}$ & $\begin{array}{c}\text { Inde } \\
\text { finid } \\
\text { a }\end{array}$ \\
\hline B1 & 2 & $\begin{array}{l}\text { Aus } \\
\text { ente }\end{array}$ & $\begin{array}{l}\text { Muda } \\
\text { de } \\
\text { orquíd } \\
\text { ea }\end{array}$ & $\begin{array}{c}\text { Veget } \\
\text { al }\end{array}$ & Lisa & No & 1 & não & $\begin{array}{c}\text { Decor } \\
\text { ação }\end{array}$ & $\begin{array}{c}\text { Camad } \\
\text { a } \\
\text { Estére } \\
0\end{array}$ & $\begin{array}{c}\text { Inde } \\
\text { finid } \\
\text { a }\end{array}$ \\
\hline B1 & 3 & $\begin{array}{l}\text { Aus } \\
\text { ente }\end{array}$ & $\begin{array}{l}\text { Livros } \\
\text { de } \\
\text { fotogra } \\
\text { fia }\end{array}$ & Papel & $\begin{array}{c}\text { Esta } \\
\text { mpad } \\
\text { a }\end{array}$ & No & 2 & não & $\begin{array}{l}\text { Uso } \\
\text { Cultur } \\
\text { al }\end{array}$ & $\begin{array}{c}\text { Camad } \\
\text { a } \\
\text { Estére } \\
0\end{array}$ & $\begin{array}{c}\text { Inde } \\
\text { finid } \\
\text { a }\end{array}$ \\
\hline B1 & 4 & $\begin{array}{l}\text { Aus } \\
\text { ente }\end{array}$ & $\begin{array}{l}\text { Livro } \\
\text { de } \\
\text { filosofi } \\
\text { a }\end{array}$ & Papel & $\begin{array}{c}\text { Esta } \\
\text { mpad } \\
\text { a }\end{array}$ & No & 1 & não & $\begin{array}{l}\text { Uso } \\
\text { Cultur } \\
\text { al }\end{array}$ & $\begin{array}{c}\text { Camad } \\
\text { a } \\
\text { Estére } \\
0\end{array}$ & $\begin{array}{c}\text { Inde } \\
\text { finid } \\
\text { a }\end{array}$ \\
\hline B1 & 5 & $\begin{array}{l}\text { Aus } \\
\text { ente }\end{array}$ & $\begin{array}{l}\text { Porta } \\
\text { control } \\
\text { e } \\
\text { remoto } \\
s\end{array}$ & $\begin{array}{c}\text { Madeir } \\
\mathrm{a}\end{array}$ & $\begin{array}{c}\text { Lisa / } \\
\text { Marr } \\
\text { om }\end{array}$ & No & 1 & não & $\begin{array}{l}\text { Decor } \\
\text { ação }\end{array}$ & $\begin{array}{c}\text { Camad } \\
\text { a } \\
\text { Estére } \\
0\end{array}$ & $\begin{array}{c}\text { Inde } \\
\text { finid } \\
\text { a }\end{array}$ \\
\hline B1 & 6 & $\begin{array}{l}\text { Aus } \\
\text { ente }\end{array}$ & $\begin{array}{l}\text { Contro } \\
\text { les } \\
\text { remoto }\end{array}$ & $\begin{array}{c}\text { Plástic } \\
0\end{array}$ & Lisa & No & 4 & não & $\begin{array}{c}\text { Entret } \\
\text { enime } \\
\text { nto }\end{array}$ & $\begin{array}{c}\text { Camad } \\
\text { a } \\
\text { Estére } \\
0\end{array}$ & $\begin{array}{c}\text { Inde } \\
\text { finid } \\
\text { a }\end{array}$ \\
\hline B1 & 7 & $\begin{array}{l}\text { Aus } \\
\text { ente }\end{array}$ & $\begin{array}{l}\text { Base } \\
\text { de } \\
\text { telefon } \\
\text { e sem } \\
\text { fio }\end{array}$ & $\begin{array}{c}\text { Plástic } \\
0\end{array}$ & Lisa & No & 1 & não & $\begin{array}{c}\text { Comu } \\
\text { nicaçã } \\
0\end{array}$ & $\begin{array}{c}\text { Camad } \\
\text { a } \\
\text { Estére } \\
0\end{array}$ & $\begin{array}{l}\text { Inde } \\
\text { finid } \\
\end{array}$ \\
\hline
\end{tabular}


Revista de Arqueologia Pública

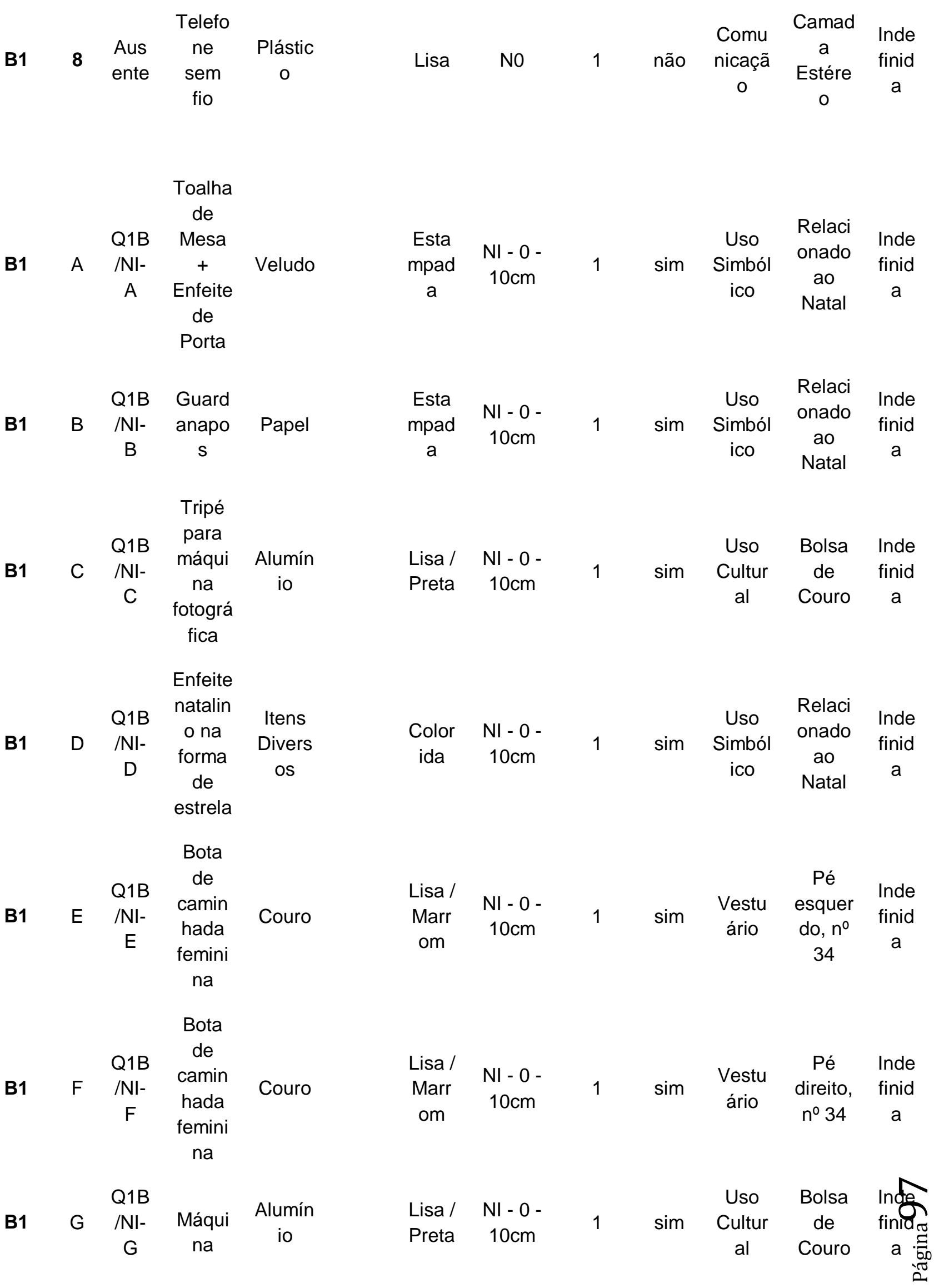


Revista de Arqueologia Pública

fotográ
fica

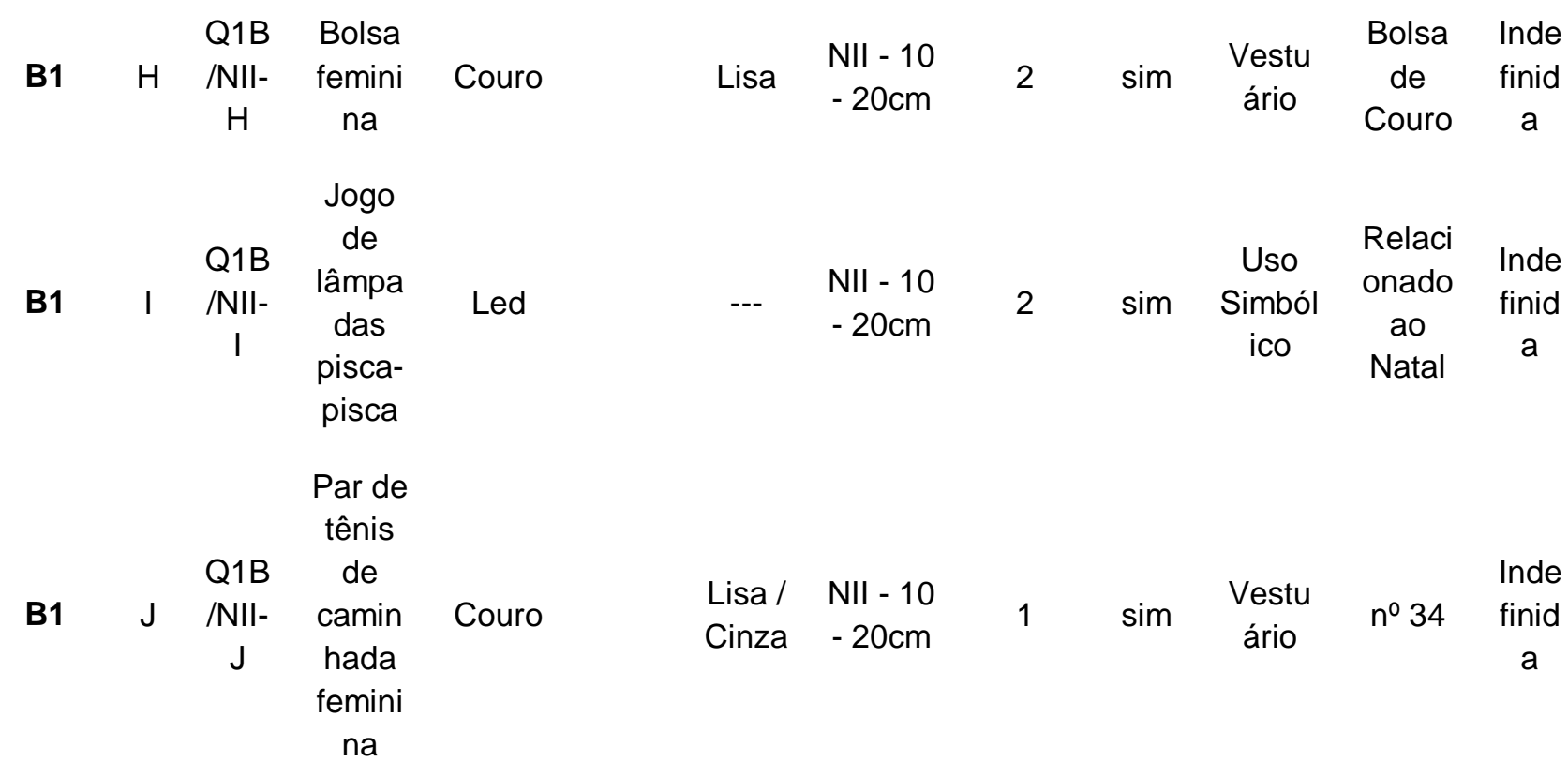

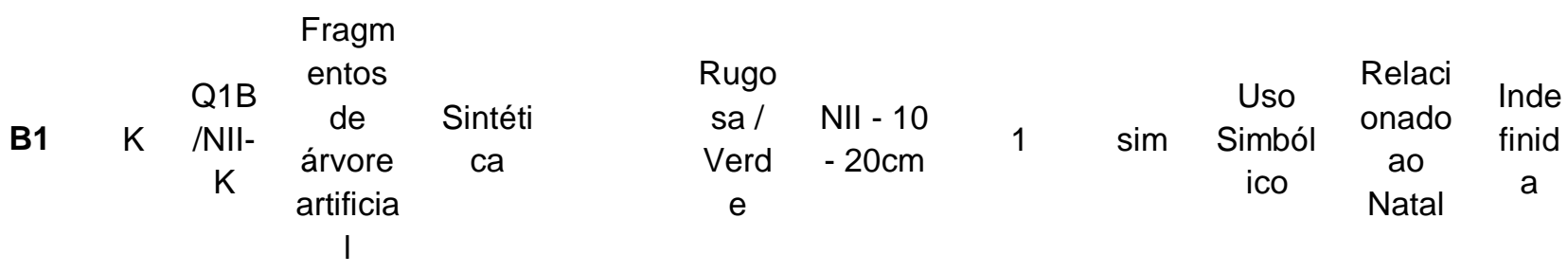

Pedest

al /

Q1B Suport

B1 L /NII- e de Metal

$\mathrm{L} \quad$ árvore

Lisa / NII - 10

Uso

Relaci

onado

Inde

artificia

e

ico

Natal

finid

I

Sachê

B1 M $\begin{array}{ccc}\text { Q1B } & \begin{array}{c}\text { odoriz } \\ \text { adll- } \\ \text { ador e } \\ \text { desum } \\ \text { idifican }\end{array} & \text { Verbe } \\ & & \end{array}$

\begin{tabular}{ccccccc} 
Esta & NII - 10 & \multirow{2}{*}{ sim } & $\begin{array}{c}\text { Preser } \\
\text { vação }\end{array}$ & $\begin{array}{c}\text { Denota } \\
\text { Cuidad } \\
0\end{array}$ & 1 \\
a & $-20 \mathrm{~cm}$ & & & & &
\end{tabular}

te

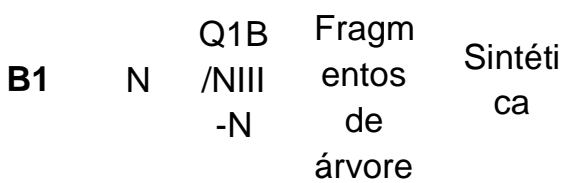

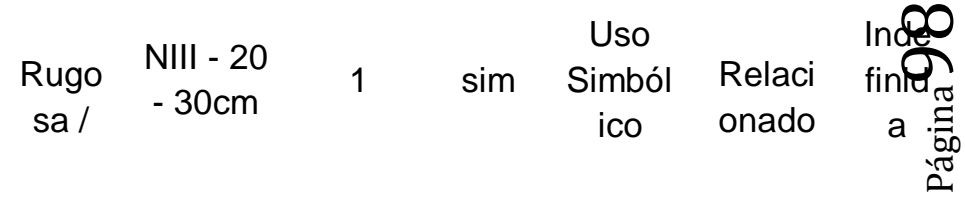

\begin{tabular}{|l|l|l|l|l|l|l|}
\hline (C) Rev. Arqueologia Pública & Campinas, SP & v. 10 & n. 1 & p. 86-108 & MAR. 2016 & ISSN 2237-8294 \\
\hline
\end{tabular} 
Revista de Arqueologia Pública

\begin{tabular}{|c|c|c|c|c|c|c|c|c|c|c|c|}
\hline & & & $\begin{array}{c}\text { artificia } \\
1\end{array}$ & & $\begin{array}{c}\text { Verd } \\
\mathrm{e}\end{array}$ & & & & & $\begin{array}{l}\text { ao } \\
\text { Natal }\end{array}$ & \\
\hline B1 & $\mathrm{O}$ & $\begin{array}{l}\text { Q1B } \\
\text { /NIII } \\
-\mathrm{O}\end{array}$ & $\begin{array}{l}\text { Fragm } \\
\text { entos } \\
\text { de } \\
\text { árvore } \\
\text { artificia } \\
\quad \text { । }\end{array}$ & $\begin{array}{l}\text { Sintéti } \\
\text { ca }\end{array}$ & $\begin{array}{c}\text { Rugo } \\
\text { sa / } \\
\text { Verd } \\
\text { e }\end{array}$ & $\begin{array}{l}\text { NIII - } 20 \\
-30 \mathrm{~cm}\end{array}$ & 1 & $\operatorname{sim}$ & $\begin{array}{l}\text { Uso } \\
\text { Simból } \\
\text { ico }\end{array}$ & $\begin{array}{c}\text { Relaci } \\
\text { onado } \\
\text { ao } \\
\text { Natal }\end{array}$ & $\begin{array}{l}\text { Inde } \\
\text { finid } \\
\text { a }\end{array}$ \\
\hline B1 & $P$ & $\begin{array}{l}\text { Q1B } \\
\text { /NIII } \\
-P\end{array}$ & $\begin{array}{l}\text { Fragm } \\
\text { entos } \\
\text { de } \\
\text { árvore } \\
\text { artificia } \\
\quad \text { । }\end{array}$ & $\begin{array}{l}\text { Sintéti } \\
\text { ca }\end{array}$ & $\begin{array}{c}\text { Rugo } \\
\text { sa / } \\
\text { Verd } \\
\text { e }\end{array}$ & $\begin{array}{l}\text { NIII - } 20 \\
-30 \mathrm{~cm}\end{array}$ & 1 & $\operatorname{sim}$ & $\begin{array}{l}\text { Uso } \\
\text { Simból } \\
\text { ico }\end{array}$ & $\begin{array}{c}\text { Relaci } \\
\text { onado } \\
\text { ao } \\
\text { Natal }\end{array}$ & $\begin{array}{l}\text { Inde } \\
\text { finid } \\
\text { a }\end{array}$ \\
\hline B1 & $Q$ & $\begin{array}{l}\text { Q1B } \\
\text { /NIII } \\
-Q\end{array}$ & $\begin{array}{l}\text { Fragm } \\
\text { entos } \\
\text { de } \\
\text { árvore } \\
\text { artificia } \\
\quad \text { । }\end{array}$ & $\begin{array}{l}\text { Sintéti } \\
\text { ca }\end{array}$ & $\begin{array}{c}\text { Rugo } \\
\text { sa / } \\
\text { Verd } \\
\text { e }\end{array}$ & $\begin{array}{l}\text { NIII - } 20 \\
-30 \mathrm{~cm}\end{array}$ & 1 & $\operatorname{sim}$ & $\begin{array}{c}\text { Uso } \\
\text { Simból } \\
\text { ico }\end{array}$ & $\begin{array}{c}\text { Relaci } \\
\text { onado } \\
\text { ao } \\
\text { Natal }\end{array}$ & $\begin{array}{l}\text { Inde } \\
\text { finid } \\
\text { a }\end{array}$ \\
\hline B1 & $\mathrm{R}$ & $\begin{array}{l}\text { Q1B } \\
\text { /NIII } \\
-R\end{array}$ & $\begin{array}{c}\text { Caixa } \\
\text { Plástic } \\
\text { a com } \\
\text { artefat } \\
\text { os }\end{array}$ & $\begin{array}{c}\text { Plástic } \\
0\end{array}$ & Lisa & $\begin{array}{l}\text { NIII - } 20 \\
-30 \mathrm{~cm}\end{array}$ & 1 & sim & $\begin{array}{l}\text { Uso } \\
\text { Simból } \\
\text { ico }\end{array}$ & $\begin{array}{c}\text { Relaci } \\
\text { onado } \\
\text { ao } \\
\text { Natal }\end{array}$ & $\begin{array}{l}\text { Inde } \\
\text { finid } \\
\text { a }\end{array}$ \\
\hline B1 & $S$ & $\begin{array}{l}\text { Q1B } \\
\text { /NIV } \\
-S\end{array}$ & $\begin{array}{l}\text { Fragm } \\
\text { entos } \\
\text { de } \\
\text { árvore } \\
\text { artificia } \\
\quad \text { । }\end{array}$ & $\begin{array}{l}\text { Sintéti } \\
\text { ca }\end{array}$ & $\begin{array}{c}\text { Rugo } \\
\text { sa / } \\
\text { Verd } \\
\text { e }\end{array}$ & $\begin{array}{l}\text { NIV - } \\
30- \\
40 \mathrm{~cm}\end{array}$ & 1 & $\operatorname{sim}$ & $\begin{array}{c}\text { Uso } \\
\text { Simból } \\
\text { ico }\end{array}$ & $\begin{array}{c}\text { Relaci } \\
\text { onado } \\
\text { ao } \\
\text { Natal }\end{array}$ & $\begin{array}{l}\text { Inde } \\
\text { finid } \\
\text { a }\end{array}$ \\
\hline B1 & $\mathrm{T}$ & $\begin{array}{c}\text { Q1B } \\
\text { /NIV } \\
-T\end{array}$ & $\begin{array}{l}\text { Fragm } \\
\text { entos } \\
\text { de } \\
\text { árvore } \\
\text { artificia } \\
\quad \text { । }\end{array}$ & $\begin{array}{l}\text { Sintéti } \\
\text { ca }\end{array}$ & $\begin{array}{c}\text { Rugo } \\
\text { sa / } \\
\text { Verd } \\
\text { e }\end{array}$ & $\begin{array}{l}\text { NIV - } \\
30- \\
40 \mathrm{~cm}\end{array}$ & 1 & sim & $\begin{array}{c}\text { Uso } \\
\text { Simból } \\
\text { ico }\end{array}$ & $\begin{array}{c}\text { Relaci } \\
\text { onado } \\
\text { ao } \\
\text { Natal }\end{array}$ & $\begin{array}{l}\text { Inde } \\
\text { finid } \\
\text { a }\end{array}$ \\
\hline B1 & U & $\begin{array}{l}\text { Q1B } \\
\text { /NIV } \\
-U\end{array}$ & $\begin{array}{l}\text { Fragm } \\
\text { entos } \\
\text { de } \\
\text { árvore }\end{array}$ & $\begin{array}{l}\text { Sintéti } \\
\text { ca }\end{array}$ & $\begin{array}{l}\text { Rugo } \\
\text { sa / } \\
\text { Verd } \\
\text { e }\end{array}$ & $\begin{array}{l}\text { NIV - } \\
30- \\
40 \mathrm{~cm}\end{array}$ & 1 & $\operatorname{sim}$ & $\begin{array}{c}\text { Uso } \\
\text { Simból } \\
\text { ico }\end{array}$ & $\begin{array}{c}\text { Relaci } \\
\text { onado } \\
\text { ao } \\
\text { Natal }\end{array}$ & 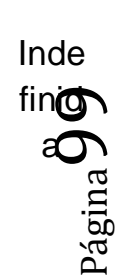 \\
\hline
\end{tabular}


Revista de Arqueologia Pública

artificia

I

Fragm

Q1B entos

B1 V $\begin{gathered}\text { NIV de } \\ -V\end{gathered}$ árvore cantét

artificia

$\begin{array}{ccccccc}\begin{array}{c}\text { Rugo } \\ \text { sa / }\end{array} & \text { NIV - } & & & \text { Uso } & \text { Relaci } & \text { Inde } \\ \text { onado } & \text { Indid } \\ \text { Verd } & 30- & 1 & \text { simból } & \text { ao } & \text { finid } \\ \text { e } & 40 \mathrm{~cm} & & & \text { ico } & \text { Natal } & \text { a }\end{array}$

I

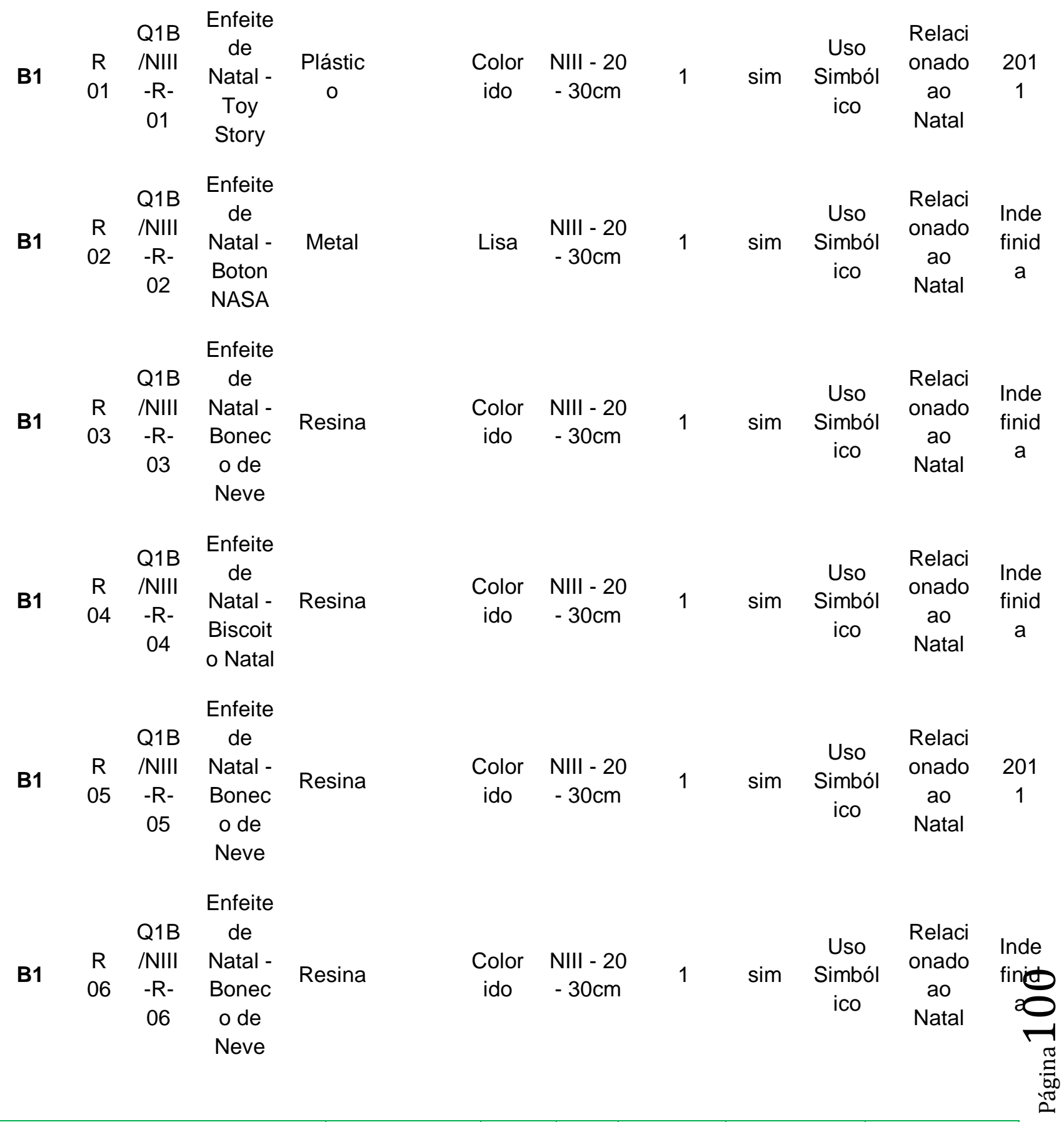




$$
\begin{aligned}
& \text { B1 } R \quad \begin{array}{rr}
\text { Q1B } & \text { Enfeite } \\
\text { de } & \text { de }
\end{array} \\
& 07 \text {-R- Natal - Resina } \\
& 07 \text { Biscoit } \\
& \begin{array}{ccccccc}
\text { Color } & \text { NIII - 20 } & \multirow{2}{*}{\text { sim }} & \text { Uso } & \text { Relaci } \\
\text { ido } & -30 \mathrm{~cm} & 1 & \text { onado } & 201 \\
\text { ico } & \text { ao } & 1 \\
& & & & \text { Natal } &
\end{array} \\
& \text { Enfeite } \\
& \text { Q1B de } \\
& 08 \text {-R- Bola Cristal } \\
& 08 \text { de } \\
& \text { Natal } \\
& \text { Q1B Enfeite } \\
& \text { B1 } \\
& \text { R /NIII de Plástic } \\
& 09 \text {-R- Natal - } 0 \\
& 09 \text { MM's } \\
& \text { Q1B Enfeite } \\
& \text { B1 } \mathrm{R} \text { /NIII } \\
& 10 \text {-R- Natal - Cristal } \\
& 10 \\
& \text { Dinoss } \\
& \text { auro } \\
& \text { Enfeite }
\end{aligned}
$$

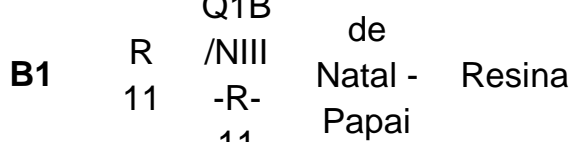

$$
\begin{aligned}
& 11 \quad \text { Papal } \\
& \text { Noel } \\
& -30 \mathrm{~cm} \\
& \text { Enfeite } \\
& \text { Q1B de } \\
& 13 \text {-R- }
\end{aligned}
$$




\begin{tabular}{|c|c|c|c|c|c|c|c|c|c|c|c|}
\hline B1 & $\begin{array}{c}R \\
15\end{array}$ & $\begin{array}{c}\text { Q1B } \\
\text { /NIII } \\
-\mathrm{R}- \\
15\end{array}$ & $\begin{array}{c}\text { Enfeite } \\
\text { de } \\
\text { Natal - } \\
\text { Ratinh } \\
\text { a } \\
\text { Bailari } \\
\text { na }\end{array}$ & Resina & $\begin{array}{l}\text { Color } \\
\text { ido }\end{array}$ & $\begin{array}{l}\text { NIII - } 20 \\
-30 \mathrm{~cm}\end{array}$ & 1 & $\operatorname{sim}$ & $\begin{array}{l}\text { Uso } \\
\text { Simból } \\
\text { ico }\end{array}$ & $\begin{array}{c}\text { Relaci } \\
\text { onado } \\
\text { ao } \\
\text { Natal }\end{array}$ & $\begin{array}{l}\text { Inde } \\
\text { finid } \\
\text { a }\end{array}$ \\
\hline B1 & $\begin{array}{c}R \\
16\end{array}$ & $\begin{array}{c}\text { Q1B } \\
\text { /NIII } \\
-\mathrm{R}- \\
16\end{array}$ & $\begin{array}{c}\text { Enfeite } \\
\text { de } \\
\text { Natal - } \\
\text { Ratos } \\
\text { na } \\
\text { Cartol } \\
\text { a }\end{array}$ & Resina & $\begin{array}{l}\text { Color } \\
\text { ido }\end{array}$ & $\begin{array}{l}\text { NIII - } 20 \\
-30 \mathrm{~cm}\end{array}$ & 1 & sim & $\begin{array}{l}\text { Uso } \\
\text { Simból } \\
\text { ico }\end{array}$ & $\begin{array}{c}\text { Relaci } \\
\text { onado } \\
\text { ao } \\
\text { Natal }\end{array}$ & $\begin{array}{c}201 \\
1\end{array}$ \\
\hline B1 & $\begin{array}{c}\mathrm{R} \\
17\end{array}$ & $\begin{array}{c}\text { Q1B } \\
\text { /NIII } \\
-\mathrm{R}- \\
17\end{array}$ & $\begin{array}{l}\text { Enfeite } \\
\text { de } \\
\text { Natal - } \\
\text { Nemo }\end{array}$ & Resina & $\begin{array}{l}\text { Color } \\
\text { ido }\end{array}$ & $\begin{array}{l}\mathrm{NIII}-20 \\
-30 \mathrm{~cm}\end{array}$ & 1 & $\operatorname{sim}$ & $\begin{array}{l}\text { Uso } \\
\text { Simból } \\
\text { ico }\end{array}$ & $\begin{array}{c}\text { Relaci } \\
\text { onado } \\
\text { ao } \\
\text { Natal }\end{array}$ & $\begin{array}{l}\text { Inde } \\
\text { finid } \\
\text { a }\end{array}$ \\
\hline B1 & $\begin{array}{c}R \\
18\end{array}$ & $\begin{array}{c}\text { Q1B } \\
\text { /NIII } \\
-\mathrm{R}- \\
18\end{array}$ & $\begin{array}{c}\text { Enfeite } \\
\text { de } \\
\text { Natal - } \\
\text { Homer } \\
\text { Simps } \\
\text { on }\end{array}$ & Resina & $\begin{array}{l}\text { Color } \\
\text { ido }\end{array}$ & $\begin{array}{l}\text { NIII - } 20 \\
-30 \mathrm{~cm}\end{array}$ & 1 & sim & $\begin{array}{l}\text { Uso } \\
\text { Simból } \\
\text { ico }\end{array}$ & $\begin{array}{c}\text { Relaci } \\
\text { onado } \\
\text { ao } \\
\text { Natal }\end{array}$ & $\begin{array}{l}\text { Inde } \\
\text { finid } \\
\text { a }\end{array}$ \\
\hline B1 & $\begin{array}{c}R \\
19\end{array}$ & $\begin{array}{c}\text { Q1B } \\
\text { /NIII } \\
-\mathrm{R}- \\
19\end{array}$ & $\begin{array}{l}\text { Enfeite } \\
\text { de } \\
\text { Natal - } \\
\text { Estatu } \\
\text { a da } \\
\text { Liberd } \\
\text { ade }\end{array}$ & Resina & $\begin{array}{l}\text { Color } \\
\text { ido }\end{array}$ & $\begin{array}{l}\text { NIII - } 20 \\
-30 \mathrm{~cm}\end{array}$ & 1 & $\operatorname{sim}$ & $\begin{array}{l}\text { Uso } \\
\text { Simból } \\
\text { ico }\end{array}$ & $\begin{array}{c}\text { Relaci } \\
\text { onado } \\
\text { ao } \\
\text { Natal }\end{array}$ & $\begin{array}{c}201 \\
1\end{array}$ \\
\hline B1 & $\begin{array}{l}R \\
20\end{array}$ & $\begin{array}{l}\text { Q1B } \\
\text { /NIII } \\
-\mathrm{R}- \\
20\end{array}$ & $\begin{array}{l}\text { Enfeite } \\
\text { de } \\
\text { Natal - } \\
\text { Rato } \\
\text { confeit } \\
\text { eiro }\end{array}$ & Resina & $\begin{array}{l}\text { Color } \\
\text { ido }\end{array}$ & $\begin{array}{l}\text { NIII - } 20 \\
-30 \mathrm{~cm}\end{array}$ & 1 & $\operatorname{sim}$ & $\begin{array}{l}\text { Uso } \\
\text { Simból } \\
\text { ico }\end{array}$ & $\begin{array}{c}\text { Relaci } \\
\text { onado } \\
\text { ao } \\
\text { Natal }\end{array}$ & $\begin{array}{l}\text { Inde } \\
\text { finid } \\
\text { a }\end{array}$ \\
\hline B1 & $\begin{array}{l}R \\
21\end{array}$ & $\begin{array}{l}\text { Q1B } \\
\text { /NIII } \\
-\mathrm{R}- \\
21\end{array}$ & $\begin{array}{l}\text { Enfeite } \\
\text { de } \\
\text { Natal - } \\
\text { MM's }\end{array}$ & $\begin{array}{c}\text { Plástic } \\
0\end{array}$ & $\begin{array}{l}\text { Color } \\
\text { ido }\end{array}$ & $\begin{array}{l}\text { NIII - } 20 \\
-30 \mathrm{~cm}\end{array}$ & 1 & $\operatorname{sim}$ & $\begin{array}{l}\text { Uso } \\
\text { Simból } \\
\text { ico }\end{array}$ & $\begin{array}{c}\text { Relaci } \\
\text { onado } \\
\text { ao } \\
\text { Natal }\end{array}$ & $\begin{array}{l}\text { Inde } \\
\text { finid }\end{array}$ \\
\hline B1 & $\begin{array}{l}\mathrm{R} \\
22\end{array}$ & $\begin{array}{l}\text { Q1B } \\
\text { /NIII }\end{array}$ & $\begin{array}{c}\text { Enfeite } \\
\text { de }\end{array}$ & Resina & $\begin{array}{l}\text { Color } \\
\text { ido }\end{array}$ & $\begin{array}{l}\text { NIII - } 20 \\
-30 \mathrm{~cm}\end{array}$ & 1 & $\operatorname{sim}$ & $\begin{array}{l}\text { Uso } \\
\text { Simból } \\
\text { ico }\end{array}$ & $\begin{array}{l}\text { Relaci } \\
\text { onado }\end{array}$ & 207 \\
\hline
\end{tabular}


-R- Natal -

22 Renas

Natal

\section{Enfeite}

Q1B de

B1

R NIII Natal

Plástic

23 -R- Minnie o

23 patina

0

dora

Enfeite

Q1B de

B1
R /NIII Natal - Plástic

$24 \quad-\mathrm{R}-$

Mickey

o

24 esquia
dor

Q1B Enfeite

B1

R /NIII de Plástic

25 -R- Natal - O

25 MM's

Q1B Enfeite

B1

R /NIII de Plástic

26 -R- Natal -

o

26 MM's

0

B1

$$
\begin{aligned}
& \text { R /NIII de Natal- Plástic } \\
& 27 \text {-R- } \\
& \text { Mickey } \\
& 0 \\
& 27 \text { e Pluto }
\end{aligned}
$$

B1

$\begin{array}{cccc}\mathrm{R} & \text { /NIII } & \text { Natal - } & \\ 28 & -\mathrm{R}- & \text { Maça } & \text { Resina } \\ & 28 & \text { Nova } & \\ & & & \\ & & \text { York } & \end{array}$

\begin{tabular}{cccc}
\multicolumn{4}{c}{ Enfeite } \\
& Q1B & de & \\
R & /NIII & Natal - & Plástic \\
29 & - R- & Mickey & o \\
& 29 & e & \\
& \multicolumn{4}{c}{ Minnie } &
\end{tabular}

Q1B

B1

$$
\begin{array}{cccc}
\mathrm{R} & \text { /NIII } & \text { Enfeite } & \\
30 & -\mathrm{R}- & \text { de } & \text { Resina } \\
& 30 & \text { Natal - } &
\end{array}
$$

$\begin{array}{ccccc}\begin{array}{c}\text { Color } \\ \text { ido }\end{array} & \begin{array}{c}\text { NIII-20 } \\ \text { idocm }\end{array} & 1 & \text { sim } & \begin{array}{c}\text { Uso } \\ \text { Simból } \\ \text { ico }\end{array}\end{array}$

Relaci onado

Inde

Natal

a

Color NIII - 20

$$
\text { ido }-30 \mathrm{~cm}
$$

Color NIII - 20

$$
\text { ido }-30 \mathrm{~cm}
$$

Color NIII - 20

$$
\text { ido }-30 \mathrm{~cm}
$$

Uso

Relaci onado Inde

sim Simból

ao

Natal finid

Relaci onado Inde ao a

Relaci onado Inde ao a 


\section{Revista de Arqueologia Pública}

Biscoit

o Natal

Enfeite

Q1B de

B1 $R$ /NIII Natal

31 -R- Bota

Resina

Color NIII - 20

Uso

Relaci

31 de

ido $-30 \mathrm{~cm}$

natal

Simból

onado

201

ico ao 1

Natal

Enfeite

R $/$ NIII de

de

$32-R$

Natal - Resina

Betty

boop

Q1B Enfeite

B1

R /NIII de Plástic

33 -R- Natal - 0

33 Pateta

0

ido $-30 \mathrm{~cm}$

Simból

ico

onado

Inde

Color NIII - 20

Uso

Relaci

onado Inde

ico Natal a

Q1B Enfeite

B1

$\begin{array}{cccc} & \text { Q1B } & \text { Enfeite } & \\ \mathrm{R} & \text { /NIII } & \text { de } & \text { Plástic } \\ 34 & - \text { R- } & \text { Natal } & \text { Toy } \\ & 34 & \text { Toy } & \\ & & \text { Story } & \end{array}$

Tabela 1: Descrição detalhada dos elementos encontrados ${ }^{4}$

O tabulamento dos dados coletados, realizado na ocasião da análise laboratorial permitiu a organização dos artefatos enquanto sua composição, descrição de uso, diversidade e disposição por nível estratigráfico.

Os resultados obtidos dessas análises são apresentados no formato de gráficos que, por sua vez, detalham não só a quantidade de cada dado analisado, mas também sua percentagem de ocorrência.

\footnotetext{
4 Os itens R01 a R34 encontravam-se armazenados no interior do Item R.
} 


\section{Revista de Arqueologia Pública}

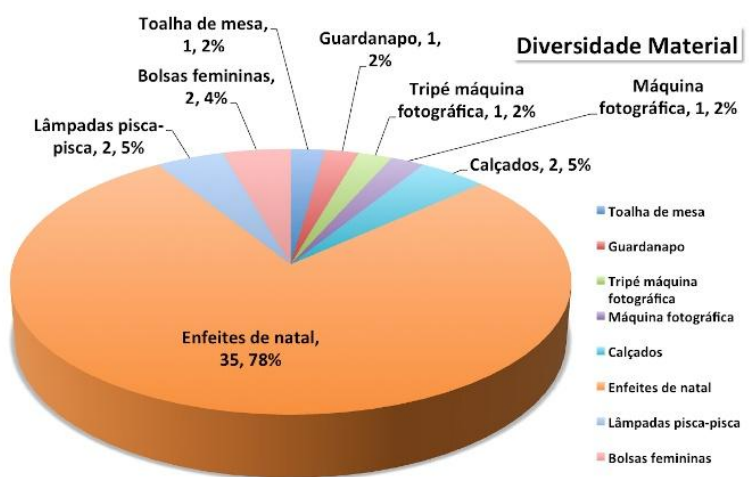

Gráfico 1 - Quantidade e percentagem da diversidade de elementos encontrados

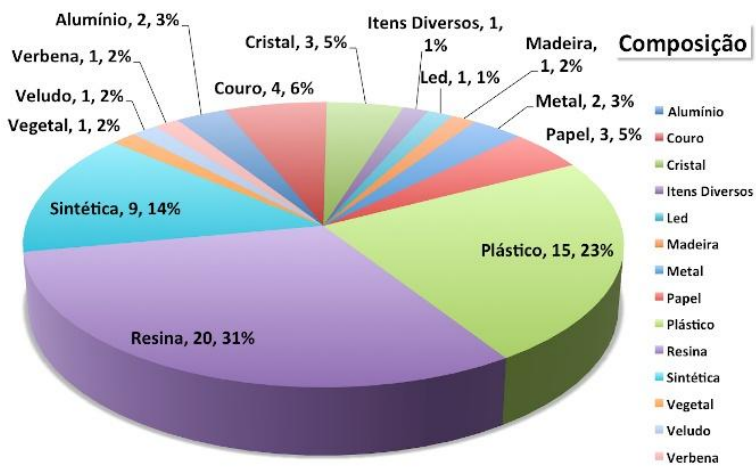

Gráfico 3 - Quantidade e percentagem da composição dos elementos encontrados

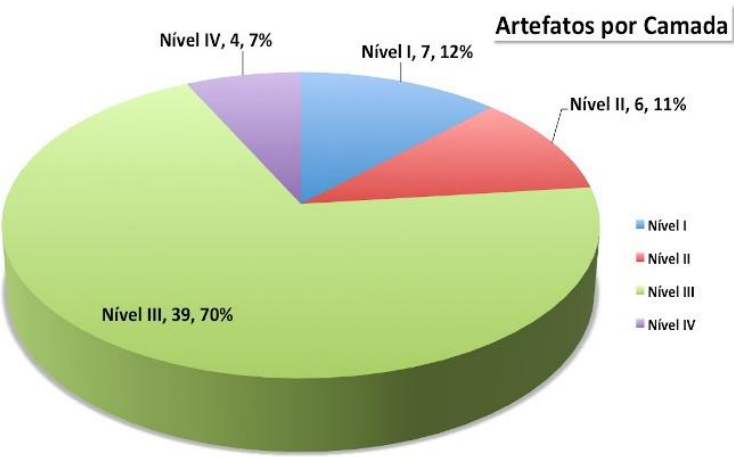

Gráfico 2 - Quantidade e percentagem de elementos encontrados em cada um dos níveis estratigráficos

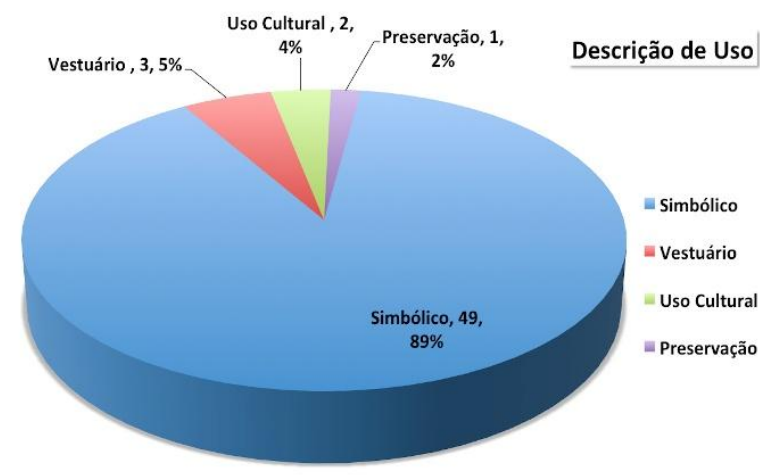

Gráfico 4 - Quantidade e percentagem do contexto de uso dos elementos encontrados

\section{CONSIDERAÇÕES FINAIS}

Quando do início das atividades de diagnóstico e prospecção das áreas aptas à escavação, verificou-se a presença de manifestações culturais e religiosas especialmente nas Quadras A, B e D localizadas no entorno da Quadricula B1, área essa que se constituiu em nosso objeto de estudo.

Com base nessas informações, procurou-se durante o processo de decapagem compreender o padrão de deposição e identificar a eventual ocorrência de correlações entre a cultura material depositada e essas práticas registradas, não só na superfície (Nível "0") da área de estudo, considerada aqui como área de intervenção direta (AID), como também nas Quadras A e D, localizadas no entorno, e consideradas aqui como área de intervenção indireta (All).

A Quadricula B1, é constituída de um baú rústico de carvalho talhado artesanalmente nas

\begin{tabular}{|l|l|l|l|l|l|l|}
\hline (C) Rev. Arqueologia Pública & Campinas, SP & v. 10 & n. 1 & p. 86-108 & MAR. 2016 & ISSN 2237-8294 \\
\hline
\end{tabular}




\section{Revista de Arqueologia Pública}

seguintes dimensões $78 \times 53 \times 47 \mathrm{~cm}$ (largura, altura, profundidade) e, de acordo com o testemunho oral da proprietária, encontra-se na família há pelo menos três gerações, tendo assumido inúmeras funções ao longo do tempo e tendo adquirido atualmente uma segunda funcionalidade, exercendo o papel de mesa decorativa.

A justificativa inicial para as escavações dessa quadrícula pousa sobre a inferência de que sua funcionalidade primeira, ou seja, aquela relacionada ao hábito de guardar bens com um determinado valor agregado, seja do ponto de vista econômico ou mesmo simbólico, ou quiçá sentimental, deva prevalecer até os dias atuais, fato que foi perfeitamente comprovado por conta da maneira como as camadas deposicionais se encontravam em repouso.

Foram encontrados, ao todo, 56 artefatos que estavam meticulosamente embalados e protegidos, e dispostos de modo a garantir sua integridade para um possível uso futuro.

Do ponto de vista econômico, não se verificou a presença de joias, tesouros e de nada valioso. O conjunto de artefatos encontrados se caracteriza de forma maciça (89\%) relacionado ao uso simbólico e ao hábito religioso do Natal. Verificou-se que o conjunto de fragmentos Q1B/NII-K, Q1B/NIIL, Q1B/NIII-N, Q1B/NIII-O, Q1B/NIII-P, Q1B/NIII-Q, Q1B/NIV-S, Q1B/NIV-T, Q1B/NIV-U e Q1B/NIV-V, depositados ao longo dos níveis II, III e IV, constituía-se em um único artefato, que após processo de restauração deu origem a uma árvore artificial, que até então poderia estar relacionada à prática religiosa do Natal, fato que veio a ser confirmado em associação a outros elementos identificados ao longo do processo de escavação: enfeites, toalhas e luzes pisca-pisca, especialmente o item "R", aflorado a partir do 3 ำ nível estratigráfico, que por sua vez, se constituía em um conjunto de 34 artefatos, destinados à decoração da referida árvore.

Além da presença maciça do contexto simbólico verificado no material escavado, verificou-se a existência de usos relacionados a questões culturais, como no caso dos artefatos Q1B/NI-C e Q1B/NI-G, tripé e máquina fotográfica, fato que denota certo grau de relação com as práticas cotidianas da sociedade atualmente existente no local, devido aos livros de fotografia encontrados no nível zero, desconsiderado no início do processo de decapagem.

Pela característica dos artefatos Q1B/NI-E, Q1B/NI-F, Q1B/NII-H e Q1B/NII-J evidenciados nos níveis I e II, podemos inferir que o processo de deposição foi praticado por uma pessoa do sexo feminino, por conta da característica inerente dos artefatos que estão diretamente relacionados à prática de vestuário. Dentre esses elementos, nota-se similaridade entre os artefatos Q1B/NI-E, Q1B/NI-F e Q1B/NII-J, uma vez que se caracterizam por calçados de caminhada com o mesmo padrão de numeração.

Nota-se associada à prática de guarda dos bens, a manifestação sentimental pelos artefatos existentes da quadricula B1, uma vez que evidenciou-se no nível II, o elemento Q1B/NII-M, um sachê odorizador e desumidificante, normalmente utilizado como agente de preservação, para inibir a

\begin{tabular}{|l|l|l|l|l|l|l|}
\hline (C) Rev. Arqueologia Pública & Campinas, SP & v. 10 & n. 1 & p. 86-108 & MAR. 2016 & ISSN 2237-8294 \\
\hline
\end{tabular}




\section{Revista de Arqueologia Pública}

degradação dos artefatos por conta da umidade. O hábito da preservação denota a importância do conjunto de artefatos e uma provável utilização cíclica dos mesmos, provavelmente anual, quando das comemorações de Natal.

O fato mais curioso que pôde ser notado após os trabalhos laboratoriais é a total falta de correlação entre os artefatos e os contextos evidenciados nas Quadras A e D, onde se verificou fortes evidências da prática religiosa contemporânea relacionada ao Budismo.

A árvore de Natal, assim como seus enfeites evidenciados na Quadricula B1, são símbolos que fazem parte de uma das mais populares tradições associadas à prática cristã de celebração do Natal, feita por católicos, protestantes ou ortodoxos. No entanto os levantamentos inicias apontam uma forte presença da tradição Budista no Sitio LQ. Tal divergência nos fez formular a seguinte pergunta: os budistas comemoram o natal?

Um jeito rápido de responder seria: "não, não comemoram, porque o natal é uma festa cristã, que comemora o nascimento de Jesus, e os budistas têm fé em Buda e seguem o seu exemplo e ensinamentos". Essa resposta parece estar correta... mas não compartilha da verdade.

O que, de fato, comemoramos no Natal? O nascimento de uma pessoa ou os seus ensinamentos, enfim o que essa data representa? $O$ fato é que na sociedade contemporânea, cada vez mais adepta de um certo grau de cosmopolitismo, não é contrassenso sugerir que o hábito de budistas se sentarem juntos aos cristãos na mesma mesa para comemorar o nascimento de Jesus é algo extremamente normal, tendo o regozijo mútuo como o principal prato a ser servido, onde o verdadeiro presente é a troca das experiências espirituais que muitas vezes são apropriadas pelo próximo como forma de fortalecimento de suas crenças pessoais e religiosas. O hábito de se montar árvore de natal pelos habitantes "Budistas" desse sítio pode ter sido adquirido por influência ancestral, apesar de se mostrar bastante recente, pois as datações de alguns dos artefatos (Q1B/NII-M, Q1B/NIIIR-01, Q1B/NIII-R-05, Q1B/NIII-R-07, Q1B/NIII-R-16, Q1B/NIII-R-19, Q1B/NIII-R-22, Q1B/NIII-R-30 e Q1B/NIII-R-31, ver Tabela 1), sugerem que a árvore foi sido montada uma única vez no Natal de 2011.

\section{REFERÊNCIAS BIBLIOGRÁFICAS}

BASTOS, R. L.; TEIXEIRA, A. Normas e gerenciamento do Patrimônio Arqueológico. São Paulo, 9a SR/IPHAN, 2005.

BLEED, P. Trees and chains, links or branches: conceptual alternatives for consideration for stone tool production and other sequential activities. Journal of Archaeology Method and Theory, 8 (01), pp. 223-237, 2001.

BRASIL. Coletânea de Legislação de Direito Ambiental, Constituição Federal / organização Odete

\begin{tabular}{|l|l|l|l|l|l|l|}
\hline (C) Rev. Arqueologia Pública & Campinas, SP & v. 10 & n. 1 & p. 86-108 & MAR. 2016 & ISSN 2237-8294
\end{tabular}




\section{Revista de Arqueologia Pública}

Medauar. - 7. Ed. Ver., atual. e ampl. - São Paulo : Editora Revista dos Tribunais, 2008. - (RT MiniCódigos).

CRESWELL, R. Prométhée ou Pandore? Propôs de ecnologie culturelle. Paris, Editions Kimé, 1996.

FAGUNDES, M. Sítio Rezende: das cadeias operatórias ao estilo tecnológico - um estudo de dinâmica cultural no médio vale do Paranaíba, Centralina, Minas Gerais. São Paulo, MAE/USP, Dissertação de Mestrado, 2004, 544p.

HARRIS, E. C. Princípios de estratigrafia arqueológica, Editorial Crítica, Barcelona (1991).

JOUKOWSKI, M. A Complete Manual of Field Archaeology: tools and techniques of field work for archaeologists. New York: Prentice Hall, 1986.

LEMONNIER, P. The study of material culture today: toward an anthropology of technical systems. Journal of anthropological archaeology, 5, pp. 147-186, 1986.

. Elements for anthropology of technology. Michigan, Museum of Anthropological Research (88), University of Michigan, 1992.

LEROI-GOURHAN, A. Vocabulaire - fouilles de Pincevent: essai D’Anacyse ethnographique dún habitat magdalenien. La section 36, CNRS, Paris, 1972.

MCINTOSH J. Guia practica de Arqueologia. Madrid: Hermann Blume, 1986.

MORAIS, J. L. A utilização dos afloramentos litológicos pelo homem pré-histórico brasileiro: análise do tratamento a matéria-prima. São Paulo, Fundo de Pesquisa do Museu Paulista da Universidade de São Paulo, Tese de Doutoramento, 1983.

WATERS, M. R. Principles of geoarchaeology: a North American perspective. Tucson: University of Arizona Press, 1992. 398 p.

\section{AGRADECIMENTOS}

Agradeço à Prof. Dra. Carolina Kesser Barcellos Dias e ao Prof. Dr. Vagner Cavalheiro Porto, assim como a UNISA e ao MAE-USP pelo apoio institucional.

A responsabilidade pelas ideias restringe-se ao autor. 